\title{
Facade Media Sebagai Alternatif Titik Reklame Pembentuk Visual Kota Semarang
}

\author{
Agustinus Dicky Prastomo \\ Desain Komunikasi Visual, \\ Universitas Katolik Soegijapranata Semarang \\ email: dicky.prastomo@unika.ac.id \\ Robert Rianto Widjaja \\ Desain Komunikasi Visual, \\ Universitas Katolik Soegijapranata Semarang \\ email: robert@unika.ac.id
}

\begin{abstract}
Simpang Lima, Pahlawan Street, Pemuda Street, Pandanaran Street, and Gadjah Mada Street now is becoming an important icon for Semarang City. The current condition shows that billboard arrangements in that area are uncluttered. More and more billboard will not make a good visual. This paper aims to provide alternative option for good vieweing in the city. A photographic survey is conducted to produce visual simulation using facade media. Relocation is needed from outside the street into building facade. The benefit using facade media will became an effective and efficient tool in the next future and expected to attract domestic or foreign tourist when visiting Semarang City. The simulation findings could give economic perpective to increase the local goverment's revenue.
\end{abstract}

Keywords: Facade Media, Reklame, Visual, Image

\begin{abstract}
Abstrak
Kota Semarang sebagai Ibu Kota Jawa Tengah memiliki ring area yang menjadi ikon penting seperti Simpang Lima, Jalan Pahlawan, Jalan Pemuda, Jalan P andanaran, dan Jalan Gadjah Mada. Kondisi terkini menunjukkan penataan dan peletakan titik-titik reklame yang belum tertata rapi dan semakin banyak j umlahnya se cara visual terkesan semrawut dan tidak i ndah. Tulisan i ni be rtujuan untuk memberi alternatif pilihan penataan titik reklame agar lebih $r$ api dan indah. Menggunakan survei fotografi pemetaan jalan yang dilakukan dari beberapa sudut menghasilkan data visual yang kemudian disimulasikan ke visual yang ingin diwujudkan. Hasil kajian visual penataan titik reklame di ke lima ring a rea tersebut menunjukkan trend relokasi dan pe nghilangan $\mathrm{t}$ itik $\mathrm{r}$ eklame. Fasade media disarankan $m$ enjadi $m$ edia al ternatif pe nyampai i nformasi y ang e fektif da $\mathrm{n} l$ ebih e fisien. Temuan simulasi k omunikasi v isual menggunakan fasade dapat menjadi al ternatif seb agai prog ram $\mathrm{j}$ angka panjang pendapatan asli daerah, kondisi ini diharapkan mampu menarik wisatawan domestik maupun mancanegara untuk mengunjungi Kota Semarang.
\end{abstract}

Kata kunci: Fasade Media, Reklame, Visual, Citra 


\section{PENDAHULUAN}

Semarang m erupakan ibu kota Jawa Tengah yang terus be rbenah. P embangunan berbagai s ektor $\mathrm{m}$ emberi kont ribusi pos itif sarana pr asarana kot a yang $\mathrm{s}$ emakin berkembang dan m emudahkan w arga unt uk berinteraksi. Di sisi lain perkembangan kota dengan s egala aktivitasnya, $\mathrm{m}$ uncul persoalan baru seperti papan-papan reklame yang me njamur di s etiap titik - titik di lingkungan kot a. T itik - titik ini di tengarai tidak ha nya $m$ uncul di pinggir $j$ alan $t$ etapi juga $\mathrm{s}$ ering $\mathrm{m}$ emanfaatkan jembatan penyeberangan, pohon, bahkan $\mathrm{p}$ erbukitan. Kondisi ini tentu merubah wajah visual kota Semarang.

Dampak berkembangnya i nformasi melalui reklame perlu diwaspadai agar tidak menganggu a ktivitas $\mathrm{w}$ arga kot a $\mathrm{m}$ aupun potensi $\mathrm{w}$ isata ba gi masyarakat di lua $\mathrm{r}$ Semarang. Secara visual bahkan trotoar atau tempat pe jalan ka ki hi ngga m enjorok k e jalan dipakai untuk memasang reklame. Hal ini jika dibiarkan tentu akan membuat wajah kota Semarang akan kotor dan semrawut.

Tujuan da ri pe nelitian i ni a dalah membentuk s imulasi visual $\mathrm{w}$ ajah kot a Semarang yang 1 ebih be rsih dan hijau dengan cara $\mathrm{m}$ enata $\mathrm{k}$ embali pe manfaatan titik reklame di jalan atau trotoar ke dalam facade media di dalam bangunan.
Bagi $\mathrm{p}$ emerintah kot a, tidak ba nyak riset untuk membantu proses penataan visual titik-titik reklame tersebut ka rena pe rspektif ekonomi m emandang keberadaan $\mathrm{t}$ itik-titik reklame $\mathrm{m}$ ampu menghasilkan pendapatan daerah. Penelitian ini aka $\mathrm{n}$ mencoba memberikan kont ribusi da ri p erspektif desain kom unikasi vi sual. $\mathrm{P}$ erspektif $\mathrm{i}$ ni salah satunya mengajak pe merintah kot a untuk menata titik -titik reklame agar tidak semrawut, be rsih, da n m embuat $\mathrm{w}$ arga kot a nyaman di kota yang hijau.

\section{TELAAH LITERATUR DAN PENGEMBANGAN HIPOTESIS}

Memperhatikan titik-titik reklame di kota $\mathrm{S}$ emarang khus usnya $\mathrm{p}$ ada a rea $\mathrm{i}$ kon kota Semarang dapat digunakan pemahaman berdasarkan teori-teori yang relevan sebagai dasar sebelum simulasi visual dilakukan.

\section{Menentukan Jarak Pandang Titik Reklame di dalam Kota}

Menurut S unarimahingsih, dkk, 2012, kesempatan yang $\mathrm{m}$ ampu dimanfaatkan untuk ke cepatan ke ndaraan $20 \mathrm{~km} \quad / \mathrm{jam}$ dalam $m$ engamati pa pan reklame ha nya 5 detik, da n unt uk kendaraan d engan kecepatan diatas $60 \mathrm{~km}$ ke sempatan yang dapat di manfaatkan ha nya 1d etik. A nalisis penentuan jarak ideal b erdasarkan temuan penelitian tersebut adalah sebagai berikut: 
Contoh:

Pengamat di $\mathrm{j}$ alan tengah kota (kecepatan

$20 \mathrm{~km} / \mathrm{jam})$

$(20 \times 1000) \mathrm{m} / \mathrm{jam}$

$20.000 \mathrm{~m} / 3600$ detik

$5,56 \mathrm{~m} /$ detik

Waktu pe ngamatan i deal a dalah 5 de tik, sehingga $\mathrm{j}$ arak $\mathrm{m}$ inimal pa pan $\mathrm{r}$ eklame adalah:

$5 \times 5,56=\mathbf{2 7 , 8} \mathbf{~ m}$

Pengamat di j alan tol(kecepatan $>60$ $\mathrm{km} / \mathrm{jam})$

$(60 \times 1000) \mathrm{m} / \mathrm{jam}$

$60.000 \mathrm{~m} / 3600$ detik

$16,67 \mathrm{~m} /$ detik

Waktu pe ngamatan i deal a dalah 5 de tik, sehingga $\mathrm{j}$ arak $\mathrm{m}$ inimal pa pan $\mathrm{r}$ eklame adalah:

\section{$5 \times 16,67=83,35$ m}

Pada j alan di m ana ke cepatan kendaraan lebih dari $60 \mathrm{~km} / \mathrm{jam}$ ( misal di jalan tol) maka penempatan papan reklame akan semakin jarang $\mathrm{d}$ an dimensi pa pan reklame akan menjadi semakin besar. Dalam kondisi tersebut maka desain papan reklame akan menjadi s emakin $\mathrm{s}$ ederhana $\mathrm{s}$ ecara visual di bandingkan $d$ engan $\mathrm{j}$ arak $\mathrm{p}$ andang yang dekat.

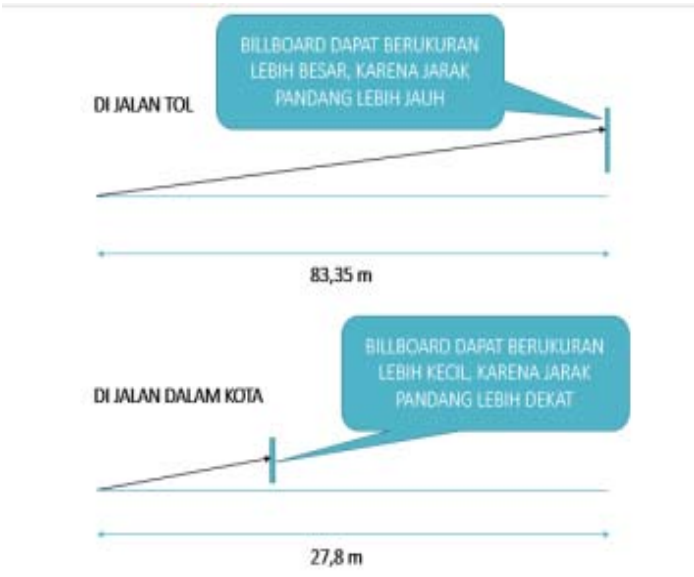

Bagan 1. Perbedaan jarak pandang di tol dan jalan dalam kota

Papan reklame $\mathrm{h}$ arus memiliki le tak yang strategis dan memberikan kenyamanan bagi $p$ engamat unt uk menerima pe san dari papan reklame tersebut. Papan reklame tidak diperkenankan j ustrum enyita pe rhatian pengamat, dan membahayakan keselamatan pengendara. B erdasarkan 1 ogika t ersebut maka pe rletakan papan reklame pa da persimpangan jalan tidak disarankan karena akan m engganggu kons entrasi pe ngendara. Sunarimahingsih, 2012 memberikan patokan jarak bagi pa pan reklame yang b erada di dekat lampu lalu lintas minimal berjarak 15 $m$ da ri titik la mpu lalu lintas. Hal ini a gar tidak $\mathrm{m}$ empengaruhi pe ngendara yang berada dipa ling de pan, s ehingga mengurangi t erjadinya ha mbatan dalam berlalu lintas. 


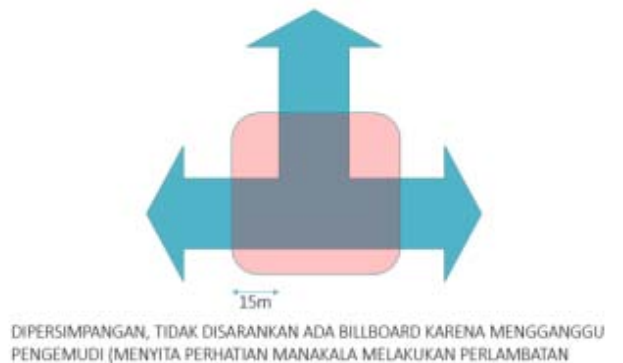

Bagan 2. Area bersih reklame dipersimpangan

Dimensi pa pan reklame yang 1 azim diterapkan a dalah $\mathrm{m}$ aksimal $50 \mathrm{~m} \mathrm{2(5 \times 10}$ m) da $n$ minimal $2 \mathrm{~m} 2(1 \times 2 \mathrm{~m} 2)$. Dimensi papan $\mathrm{r}$ eklame di tentukan ol eh be berapa faktor:

a. Jarak pandang pe ngamat t erhadap papan reklame. Papan reklame be rskala kot a akan memiliki di mensi le bih besar dengan papan reklame berskala manusia.

b. Konteks 1 ingkungan s ekitar pa pan reklame t ersebut. Papan reklame t idak diharapkan $m$ erusak vi sual 1 ingkungan yang a da, de ngand emikian di mensi papan $\mathrm{r}$ eklame ha rus disesuaikan a gar serasi dengan 1 ingkungannya. $\mathrm{C}$ ontoh: papan reklame yang berada di lingkungan konservasi, maka m enyesuaikan dimensinya dengan lingkungan yang ada. Agar tidak mengganggu secara visual.

\section{Komunikasi Visual Papan Reklame}

Papan reklames ebagai $\mathrm{m}$ edia komunikasi massa termasuk di da lam E GD (environmental Graphic Design).EGD selayaknya $\mathrm{m}$ enciptakan $\mathrm{s}$ inkronisasi da $\mathrm{n}$ peran $\mathrm{s}$ aling $\mathrm{m}$ endukung antara tempat, media komunikasi da $\mathrm{n}$ pesan yang disampaikan.

Menurut C alori, (2007), da lam E GD terdapat tiga komponen penting yang saling terkait yaitu:

a. tempat(placemaking), yang m enciptakan citra tempat yang khas dan spesifik.

b. penanda(signage),yang mengarahkan orang di da lam s uatu tempat da $n$ menuntun mereka pada kejelasan arah.

c. interpretasi(interpretive), yang menjelaskan tentang ce rita/makna s uatu tempat.

Ketiga ha 1 te rsebut s aling mempengaruhi di da lam m enciptakan komunikasi vi sual yang ba ik pa da s uatu lingkungan.

Media komunikasi vi sualy ang ditempatkan pa da s ebuah 1 ingkungan, apabila direncanakan secara baik dan benar, otomatis a kan menjadi ba gian dari lingkungan $\mathrm{t}$ ersebut. $\mathrm{H}$ al i ni di sebabkan karena t empat da n masyarakat yang be rada di s ana a kan $\mathrm{s}$ angat $\mathrm{m}$ empengaruhi pr oduk media $t$ ersebut. Berbagai $r$ iset ha rus dilakukan unt uk m enemukan $\mathrm{j}$ awaban $\mathrm{d}$ ari setiap permasalahan kom unikasi yang berada di $\mathrm{s}$ ana. Perancangan media komunikasi visual di suatu lingkungan pada akhirnya a kan $\mathrm{m}$ enjadi s umber i nformasi yang "jujur" b agi 1 ingkungan da $n$ 
meningkatkan ki nerja $\mathrm{t}$ empat $\mathrm{t}$ ersebut. Apabila s ebuah tempat memiliki ni lai yang sangat tinggi ( misal: lingkungan tradisional atau konservasi), maka cer minan nilai tersebut juga seyogyanya ada pada tampilan komunikasi visualnya.

Menemukan keselasaran dan keutuhan antara ni lai t empat de ngan desain media komunikasi vi sual i nilah yang $\mathrm{m}$ enjadi tujuan da ri riset-riset yang di lakukan. Sehingga penilaian terhadap kualitas sebuah media kom unikasi vi sual tida $\mathrm{k}$ lagi te rletak pada fisik tampilan semata namun juga pada peran da $\mathrm{n} d$ aya gunanya ba gi ke seluruhan lingkungan tempat media tersebut berada.

Dalam upa yanya untuk 1 ebih membidik pa da pe ngamat, $m$ aka t elah pul a dikembangkan $\mathrm{m}$ edia komunikasi vi sual yang me mpertimbangkan faktor ma nusiawi sebagai aw al ga gasannya. Dengan mempertimbangkan jangkauan keterbacaan, dan $\mathrm{t}$ ingkat pe mahaman $\mathrm{i}$ nformasi $\mathrm{m}$ aka dapat dibedakan antara pesan papan reklame yang berskala manusia dan berskala kota.

Papan reklame be rskala $\mathrm{m}$ anusia berukuran 1 ebih ke cil da $\mathrm{nm}$ emberikan peluang ba gi pe ngamat unt uk m encermati dengan leluasa pe san yang di sampaikan tanpa terganggu oleh waktu dan kepentingan orang 1 ain. S ebagai co ntoh adalah papan reklame yang da pat d ikembangkan pada halte bi s ( tempat or ang m enunggu), pa pan pengumuman kota, jembatan penyeberangan orang dll.

Papan reklame b erskala kot a ad alah papan reklame yang $\mathrm{k}$ eterbacaannya diharapkan mampu didapat dalam jarak yang cukup jauh (>20 m ). Ppan reklame berskala kota $\mathrm{t}$ idak di harapkan $\mathrm{m}$ engandung informasi s angat de tail ka rena pa engamat memiliki ke terbatasan w aktu untuk mengamatinya. $\mathrm{K}$ ondisi s kala kot a mengakibatkan papan $\mathrm{r}$ eklame me miliki nilai kom petitif yang tinggi da $\mathrm{n} \mathrm{s}$ aling berlomba unt uk m endapatkan kondi si keterbacaan yang $\mathrm{t}$ inggi $\mathrm{m}$ elalui pos isi da $\mathrm{n}$ sudut pa ndang yang pr ima ba gi pe ngamat. Justru hal s emacam i ni m enyebabkan tata letak papan $r$ eklame menjadi cend erung kurang terkontrol.

Dalam duni a kom unikasi visual dikenal $\mathrm{j}$ uga kom unikasi vi sual yang dinamakan ambience media, yaitu menggunakan vi sual yang t elah a da unt uk berkomunikasi ke pada pe ngamat. $\mathrm{M}$ edia semacam $\mathrm{i}$ ni s angat kont ekstual da $\mathrm{n}$ memiliki ni lai ke unikan yang tin ggi. Media ini be lum ba nyak di gunakan di I ndonesia namun s udah ba nyak di terapkan di ne garanegara maju.

\section{Regulasi Teknis Terkait Titik-Titik Reklame}

Berikut i ni ada lah pasal-pasal da ri Peraturan M enteri P U no 20/ PRT/M/2010 
yang t erkait de ngan i klan da $\mathrm{n} r$ eklame di jalan raya, dan terkait dengan kajian evaluasi tataletak papan reklame:

\section{Pasal 1}

Ayat 15 Iklan a dalah media da lam be ntuk apapun yang di gunakan pr odusen unt uk memperkanalkan suatu produk ke kha layak umum.

Ayat 16 media i nformasi ada lah media dalam be ntuk apapun yang $\mathrm{t}$ idak b ersifat komersial.

\section{$\underline{\text { Tanggapan }}$}

Berdasarkan pada t eks pada pa sal di atas, maka pa da $\mathrm{s}$ aat aka $\mathrm{n}$ menerapkan sebuah iklan pa da m edia yang ada t idak dapat di katakan sebagai m edia i nformasi, tetapi 1 ebih pa da M EDIA IKLAN. D engan demikian maka da pat di berikan pembedaan titik yang digunakan sebagai
a. Media Iklan dan
b. Media informasi

dari sini juga dapat nantinya dibuat pembeda untuk titik lokasi pe masangan a pakah a kan dibedakan a ntara 1 okasi unt uk m edia i klan atau media informasi.

\section{Pasal 3}

Lingkup pe ngaturan $p$ emanfaatan $d$ an penggunaan bagian-bagian jalan kecuali Bagian-bagian jalan tol meliputi:

a. pemanfaatan ruang $m$ anfaat $j$ alan dan ruang $\mathrm{m}$ ilik $\mathrm{j}$ alan $\mathrm{s}$ elain pe runtukannya meliputi ba ngunan da $\mathrm{n}$ jaringan ut ilitas, iklan, media informasi, bangun-bangunan dan ba ngunan gedung di da lam $\mathrm{r}$ uang milik jalan;

b. penggunaan ruang $\mathrm{m}$ anfaat $\mathrm{j}$ alan yang memerlukan $\mathrm{p}$ erlakuan khusus $\mathrm{t}$ erhadap konstruksi $\mathrm{j}$ alan da $\mathrm{nj}$ embatan be rupa muatan da $\mathrm{n}$ ke ndaraan dengan di mensi, muatan s umbu t erberat da $\mathrm{n} / \mathrm{atau}$ be ban total melebihi standar; dan

c. Penggunaan $r$ uang $p$ engawasan jalan yang tidak mengganggu keselamatan pengguna jalan dan keamanan kons truksi jalan.

\section{$\underline{\text { Tanggapan }}$}

Dari pa sal di at as but ir a m enyatakan bahwa pa pan iklan dan reklame da pat diletakkan pa da bi dang bangunan, $\mathrm{j}$ aringan utilitas ha nya s aja ha rus me mperhatikan konstruksi ob yek yang a kan di tempelinya baik berupa $\mathrm{j}$ embatan, $\mathrm{b}$ angunan atau jalan yang akan digunakan.

a. Namun saat akan menggunakannya perlu memperhatikan butir $\mathrm{C}$ y aitu Tidak mengganggu ke selamatan pe ngguna jalan.

b. Keselamatan di sini di artikan bahwa papan i klan j angan s ampai m enutupi informasi 1 ain yang akan m engganggu pandangan, baik iu nama tempat ataupun penunjuk arah dan rambu lalu lintas yang lain. 


\section{METODE PENELITIAN}

Metode pe nelitian di sini m erupakan langkah-langkah serta pendekatan penelitian yang di lakukan. $P$ engumpulan da ta $\mathrm{d}$ an informasi dilakukan dalam dua cara:

a. survei 1 apangan unt uk $\mathrm{m}$ engetahui kondisi fisik papan reklame serta kualitas perletakannya.

b. Survei i nstansional di lakukan unt uk memperoleh data-data s ekunder, ba ik data-data num erik m aupuun da ta-data (dokumen) ke bijakan da n pe raturanperaturan yang $\mathrm{t}$ erkait de ngan perencanaan papan reklame.

\section{Simulasi Visual Perubahan Papan Reklame}

Membuat simulasi vi sual te ntang pemindahan titik papan reklame yang berada di area sarana da n prasarana kot a ke da lam kavling $\mathrm{b}$ angunan. S imulasi di lakukan dengan $\mathrm{m}$ enggunakan $\mathrm{t}$ eknologi di gital. Survey da $\mathrm{n}$ pengamatan lapangan. S urvey dilakukan dengan merekam semua titik papan reklame yang ada sesuai dengan kondisi di lapangan.

Produk survey:

a. Denah titik papan reklame (melengkapi data yang s udah ada). P engambilan foto harus disertai dengan keterangan titik pengambilannya, da $\mathrm{n}$ tertera di da lam peta.

b. Foto setiap "sekuen" pa pan reklame dengan memperlihatkan lingkungannya. (Maksud pengambilan foto, a dalah untuk memperlihatkan konteks papan reklame dengan lingkungannya, $\mathrm{j}$ adi bukan berfokus pada desain papan reklame). Foto tersebut akan di pakai untuk bahan simulasi vi sual pe mindahan posisi papan reklame dari trotoar ( atau sarpras kota lainnya) kedalam kavling bangunan.

- Pengambilan foto dengan kualitas informatif yang baik sebanyak:

o J1. Pemuda (18 titik)

o Jl. Pandanaran (18 titik)

o Jl.GadjahMada (18 titik)

o Jl. Pahlawan (10 titik)

o Simpang Lima (10 titik)

- Setiap titik pengambilan foto dilkukan 6 kali pemotretan yaitu dari arah tengah jalan dan dari arah kanan dan kiri jalan

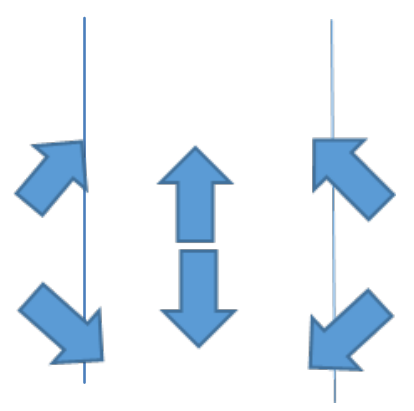

Bagan 3. Mapping fotografi dari beberapa sudut 


\section{Analisis dan evaluasi data}

Data yang sudah diperoleh baik sekunder (dari Dinas terkait) maupun primer (survey lapangan, pengambilan foto, dsb) kemudian dianalisis dan dilakukan evaluasi data. Hasilnya kemudian di tuangkan dalam buku laporan.

\section{HASIL PENELITIAN DAN PEMBAHASAN}

Kajian ini me ngambil kasus s tudi jl Gadjahmada, J 1. P emuda, J 1. P andanaran, Simpang 1 ima da $\mathrm{n}$ Jl. P ahlawan dengan beberapa pertimbangan:

1. Penggal jalan tersebut sangat berpotensi untuk diadakan papan reklame. Tercatat sejumlah 139 titik papan reklame tersebur di kelima ruas jalan tersebut. (44 di jalan gadjahmada, 30 titik di jlpemuda, 35 titik di jlpandanaran, 25 titik di Simpang lima, dan 5 titik di jlpahlawan).

2. Daerah tersebut adalah daerah pusat bisnis ( CBD) kot a S emarang s ehingga kecenderungan perkembangan kedepan perlu diantisipasi.

3. Apabila di ke lima penggal jalan tersebut papan reklame dapat ditata dengan baik maka kemungkinan akan lebih mudah menata papan reklame di pe nggaljalan yang 1 ain. $M$ etoda dan pemecahannya dapat diturunkan secara tipikal.

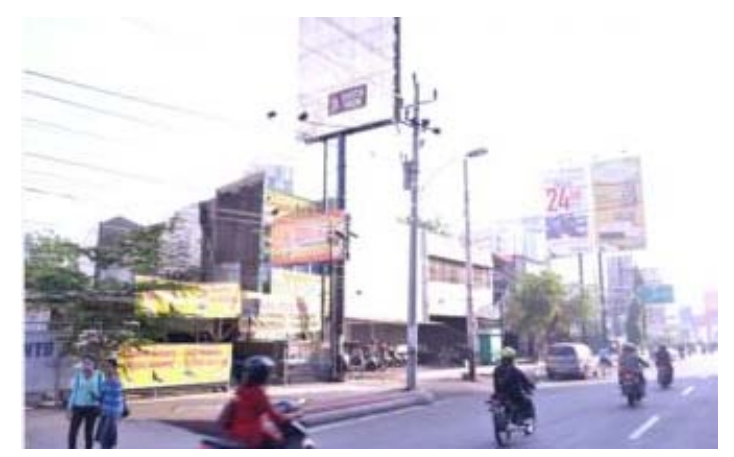

Gambar 1. dok.mapping fotografi

Penggal j alan Gadjah $\mathrm{M}$ ada pada gambar 1, sebagian sudah menempati fasade media di da lam ba ngunan. S ebagian tidak dan mengangganggu visual secara umum.

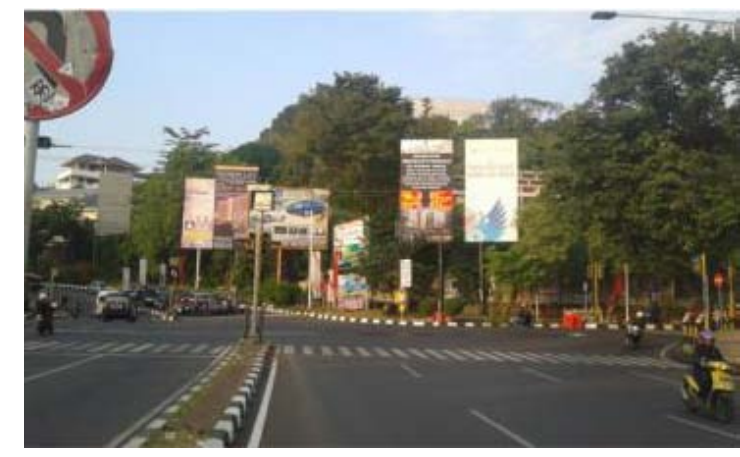

Gambar 2. dok.mapping fotografi

Penggal j alan Pahlawan pada g ambar $2, \mathrm{t}$ erdapat pot ensial $\mathrm{t}$ itik pe nempatan reklame s ecara kom ersial, tetapi m enjadi semrawut dan kotor.

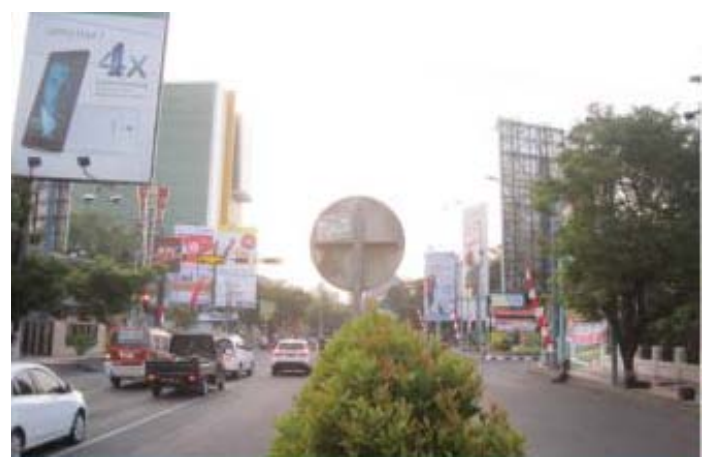

Gambar 3. dok.mapping fotografi 
Penggal jalan Pandanaran di gambar 3, didominasi ol eh pa pan r eklame di s arana prasarana $\mathrm{j}$ alan da $\mathrm{n} \mathrm{t}$ idak a tau be lum $\mathrm{t}$ entu memungkinkan di pindahkan ke da lam bidang media fasade bangunan.

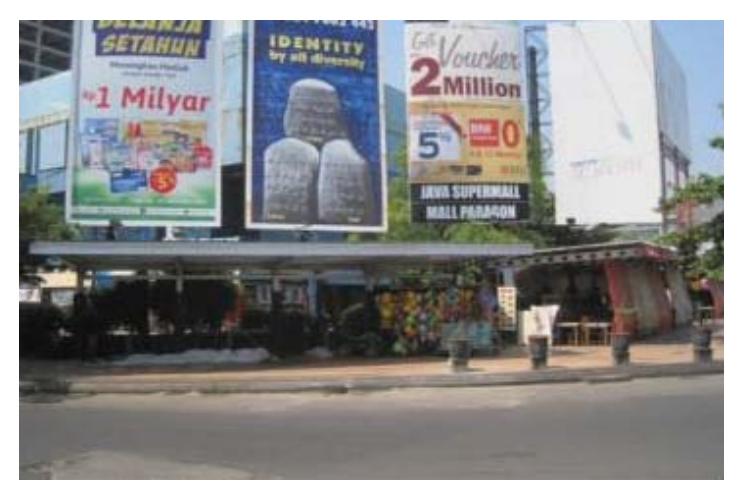

Gambar 4. dok.mapping fotografi

Penggal j alan Simpang Lima, memungkinkan unt uk di pindhkan ke da lam media $\mathrm{f}$ asade $\mathrm{k}$ arena $\mathrm{m}$ asih ada $\mathrm{t}$ empatnya tetapi dengan mengubah dimensi desain agar tidak menutupi bangunan yang ada

Melihat be berapa ka sus di at as s ecara cermat, setiap titik papan reklame memiliki kasus yang b erbeda-beda s ehingga penanganannya juga berbeda satu sama lain. Evaluasi da lam $\mathrm{t}$ ulisan ini $\mathrm{m}$ encoba unt $\mathrm{uk}$ fokus pa da $\mathrm{p}$ enanganan $\mathrm{t}$ itik-titik reklame yang pe rlu di desain ul ang da $\mathrm{n}$ di pindahkan ke da lam m edia $\mathrm{f}$ asade ba ngunan. Hal i ni diupayakan unt uk m empermudah s imulasi dan pertimbangan desain serta kemungkinan ekonomi yang menyertainya.

Sesuai de ngan pe ngamatan um um yang s udah di lakukan,maka da pat dirangkumkan be berapa $\mathrm{m}$ odel permasalahan di 1 apangan yang be rkaitan dengan pemindahan titik papan reklame dari sarana prasarana kota kedalam media fasade sebagai berikut:

a. Perumahan, bi sa di negosiasi, $m$ emiliki halaman, tetapi t etap be rgantung k epada si pe milik rumah apakah halaan atau bidang fasade di $r$ umahnya bol eh dipasang reklame.

b. Gedung kom ersial, b isa di negosiasi, tergantung $\mathrm{m}$ ateri reklame $\mathrm{y}$ ang ditampilkan seperti ma 11 a tau pusat perbelanjaaan. Bagi pe milik yang tida $\mathrm{k}$ memperkenankan umumnya ka rena pertimbangan kons truksi m edia r eklame yang membahayakan.

c. Gedung $P$ emerintahan, $t$ idak bi sa dinegosiasi ka rena akan $\mathrm{m}$ erubah c itra atau image pe merintahan, kecuali kepentingan tertentu yang relevan.

d. Tempat $i$ badah, $t$ idak bisa di negosiasi karena bi sa m erubah citra tempat ibadah menjadi w ahan kom ersial ke cuali unt uk kepentingan tertentu.

e. Tanah kosong di s ekitar s arana prasaran kota, bi sa di negosiasi s ejauh pi hak pemilik ba ik s wasta m aupun pe merintah memperbolehkan. Negosiasi da lam konteks i ni pe rlu di kaji 1 ebih 1 anjut karena bersifat kontekstual untuk masingmasing kasus dan persoalan yang muncul. 


\section{Simulasi Visual Papan Reklame}

Berdasarkan dari pe ngamatan pa da 5 koridor jalan yang ada terkait dengan Papan Reklame, koridor j alan G ajahmada, jalan Pemuda, J alan $\mathrm{P}$ andanaran, $\mathrm{S}$ impang 1 ima dan Jalan Pahlawan, permasalahan reklame yang paling ke cil ada pa da jalan Pahlawan, karena pa da ko ridor j alan i ni pa ling s edikit papan reklame yang ada. Hal ini mengingat karena pa da kor idor $\mathrm{j}$ alan ini ada lah jalan protocol/jalan utama yang ma yoritas bangunannya a dalah ba ngunan $t$ ingkat propinsi.

Sedangkan unt uk pe nggal $\mathrm{j}$ alan yang lain, rata-rata me miliki pe rmasalahan yang sama,m yaitu adanya ( jika tida $\mathrm{k}$ bisa dikatakan ba nyak) $\mathrm{p}$ apan $\mathrm{r}$ eklame yang mengganggu vi sual kor idor $\mathrm{j}$ alan a tau suasana kota.

Hal yang menjadi pe rmasalahan yang paling banyak adalah reklame yang merusak tampilan s uasana kot a ka rena be rbagai gedung yang $\mathrm{s}$ udah di desain sedemikian rupa kemudian menjadi tertutup tampilannya dengan papan reklame yang ada. Hal yang kemudian menjadi p ermasalahan yang dibahas pa da pe mbahasan i ni a dalah pa pan reklame yang $\mathrm{m}$ embuat pe nguna $\mathrm{j}$ alan (pejalan kaki) menjadi tidak nyaman, karena daerah pedestrian yang s emestinya digunakan s ebagai $\mathrm{j}$ alur pe jalan ka ki t ibatiba m uncul t iang pe nyangga $r$ eklame pa da bagian tengah $\mathrm{n}$ ya. $\mathrm{H}$ al $\mathrm{i}$ nis elain mengurangi ha 1 pe ngguna pe destrian $\mathrm{j}$ uga membuat ta mpilan visual da ri s ebuah koridor jalan menjadi berkurang.

Hal y ang menjadi pe rmasalahan berikutnya $t$ erkait de ngan ada nya pa pan reklame a tau pa nggung s panduk di $\mathrm{j}$ alan adalah ketidak ef ektif a $\mathrm{n}$ dari pe san yang disampaikan. $\mathrm{H}$ al yang $\mathrm{m}$ enjadi permasalahan adalah dekatnya $j$ arak antar papan reklame at au banyaknya pe san y ang muncul s ecara be rsamaan pada s ebuah panggung s panduk. $\mathrm{S}$ elain $\mathrm{t}$ idak $\mathrm{n}$ yaman untuk di lihat $\mathrm{j}$ uga akan $\mathrm{m}$ engganggu konsentrasi pe ngguna $\mathrm{k}$ endaraan $\mathrm{b}$ ermotor, karena s ecara ps ikologis or ang ak an mencoba unt uk m endapatkan i nformasi sebanyak-banyaknya dari sebuah perangsang visual yang a da di s epanjang kor idor $\mathrm{j}$ alan yang diamati.

Permasalahan yang cukup spesifik terkait de ngan permasalahan kerapatan perletakan yang paling tinggi ada di kawasan SImpanglima, dimana $p$ ada 1 okasi t ersebut papan reklame da pat dijumpai muncul pa da jarak tidak sampai 5 m eter, dan yang paling renggang hanya sejauh 15 meter. Hal ini bisa dipastikan pada saat Simpanglima lancer dan tidak mengalami kemacetan, maka informasi yang ad a pada pa pan reklame tersebut tidak tersampaikan pesannya. 
Pada kor idor $\mathrm{j}$ alan $\mathrm{P}$ emuda, $\mathrm{j}$ alan Gajahmada d an jalan Pandanaran permasalahan yang $\mathrm{m}$ uncul di antaranya adalah penyangga pa pan $\mathrm{r}$ eklame yang ad a pada $\mathrm{j}$ alur pe destrian, papan reklame yang baik da ri $1 \mathrm{~s}$ isi t etapi t idak ba ik da ri $\mathrm{s}$ isi yang 1 ain da $\mathrm{n}$ p apan reklame yang te rlalu tinggi me njulang $\mathrm{d}$ an dirasa tida $\mathrm{k}$ nyaman secara vi sual karena mengganggu vista kota / vista koridor jalan yang ada.

Dengan melihat da ri permasalahan yang ada maka perlu untuk dipikirkan solusi pemecahan yangm engutamakan pada tercapainya vi sta yang baik unt uk kor idor jalan yang menjadi titik pengamatan.
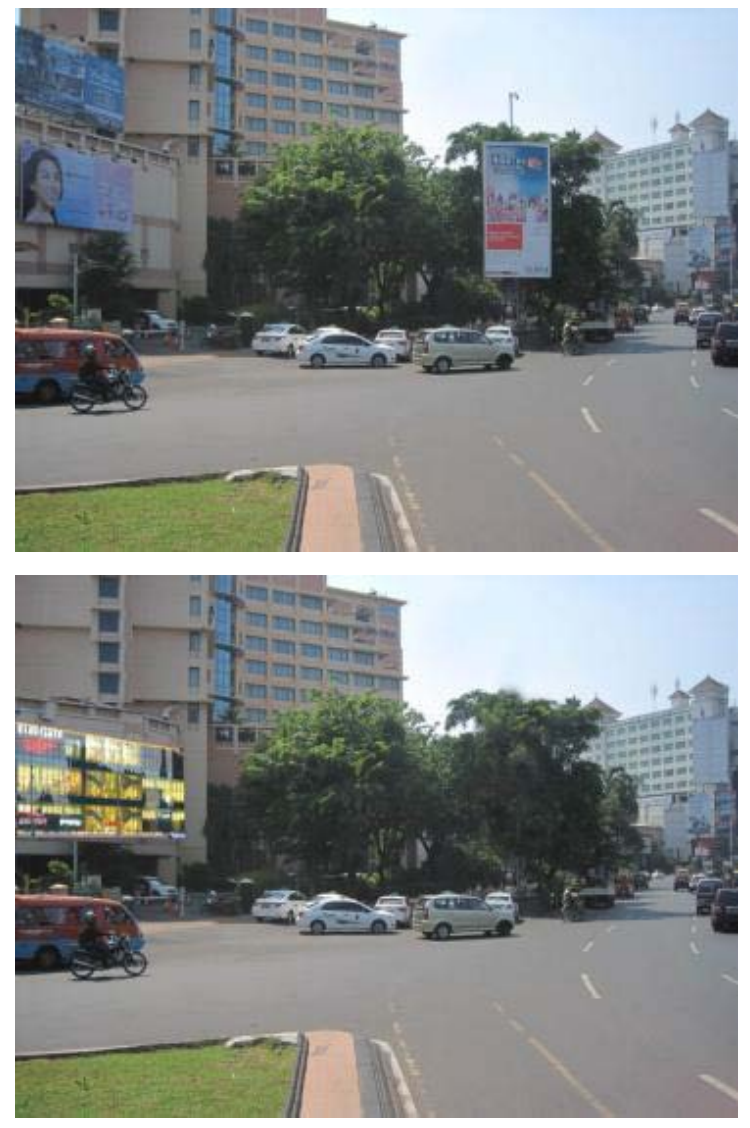

Gambar 5. dok. Simulasi Visual
Pada contoh titik reklame di Simpang Lima pada gambar 5, perlu dihilangkan dari area hijau yang ada di sarana prasarana kota. Agar vi sual kot a te rtata c antik. D iusulkan untuk direlokasi, atau dilakukan penyesuaian ukuran da $\mathrm{n} \mathrm{m}$ enggunakan $\mathrm{f}$ asade $\mathrm{m}$ edia dengan ukuran ba ru sepanjang dan setinggi pagar / ba ngunan $\mathrm{t}$ alud $\mathrm{s}$ arana pr asarana / dikecilkan ukurannya
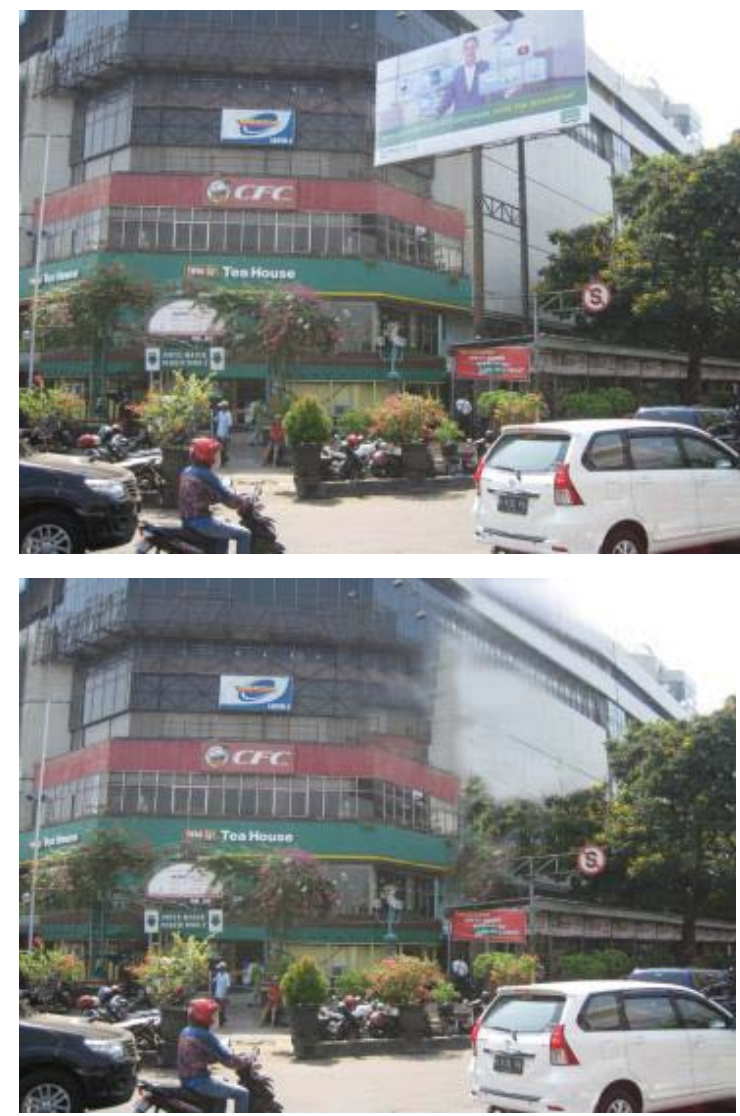

Gambar 6. dok. Simulasi Visual

Tampak pada gambar 6, visual kot a atau wajah yang $\mathrm{t}$ idak bersih dan rapi ketidakharmonisan antara pe masangan reklame d engan bangunan komersial da $n$ taman kota s erta s arana pe jalan kaki di 
sekitarnya. S imulasi penghilangan da $n$ pemindahan de nga uk uan a tau di mensi memanjang $\mathrm{s}$ esuai $\mathrm{f}$ asade $\mathrm{m}$ edia ak an menjadi lebih baik dan rapi.
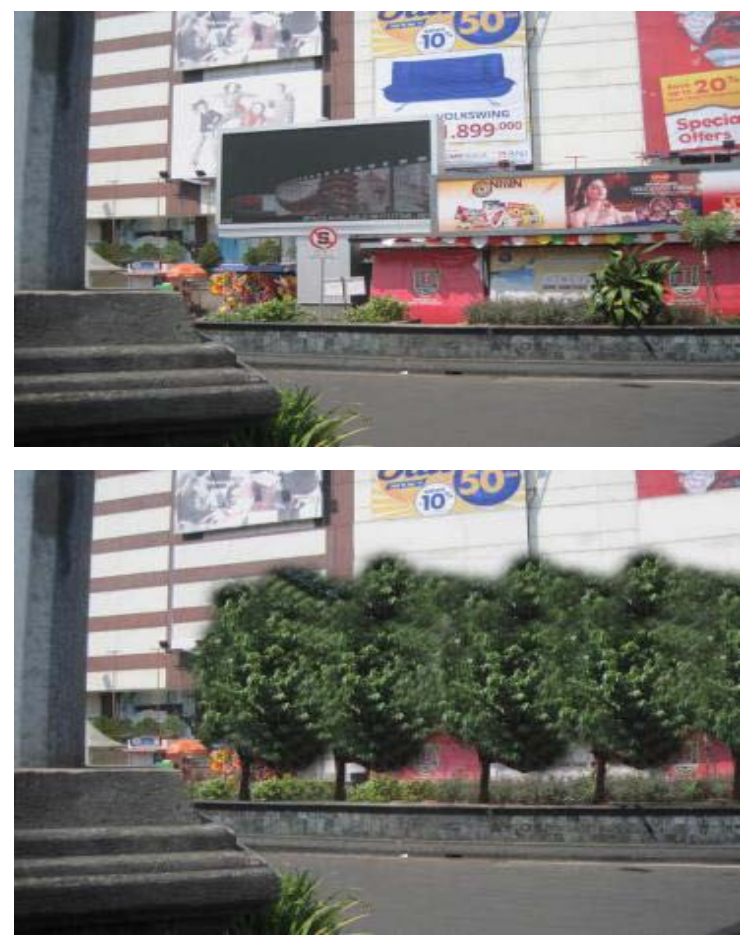

Gambar 6. dok. Simulasi Visual

Persoalan be rikut a dalah $\mathrm{t}$ umpang tindih, da $\mathrm{nm}$ unculnya vi deotron yang menggunakan $t$ eknologi e lektronik. F ungsi videtron s ebagai pa pan reklame s ebetulnya dapat di gandakan 1 ebih e fisien de ngan memasukkan materi $\mathrm{p}$ apan reklame 1 ain disampingnya. Gagasan lainnya adalah mengurangi / me nghilangkan materi pa pan reklame yang be rsifat s till/ di am ke da lam papan reklame vi deotron tetapi t etap memindahkan vi deotron da $\mathrm{n}$ erubah s kala ukurannya agar fit dengan fasade bangunan

\section{Memindahkan Papan Reklame ke dalam Media Fasade}

Memindahkan papan reklame yang ada di $\mathrm{j}$ alan / $\mathrm{f}$ asilitas um um ke $\mathrm{f}$ asade bangunan, tentunya de ngan $\mathrm{t}$ etap memperhatikan aspek es tetika $f$ asade bangunan yangt erjadi ke tika $r$ eklame dipindahkan ke ba gian $\mathrm{t}$ ampak de pan bangunan. $\mathrm{D}$ alam pa ndangan $\mathrm{S}$ uryono Herlambang s eperti di kutip R obin $\mathrm{H}$ artanto (2013: 66) , m emindahkan pa pan r eklame seringkali m emerlukan alat-alat be rat. Pada saat pemasangan, banyak bahan material tak sesuai de ngan berat, ke tebalan, dan ukurannya. A kibatnya sering goyang da $n$ roboh ketika terkena angin atau hujan.

Ruang K ota m erupakan ruang publik, sehingga ka lau m emang i ngin di jadikan komersial ha rus a da ke bijakan be sar yang mendasarinya, dan untuk kepentingan publik bukan sekedar pe ngusaha $r$ eklame. Identifikasi pe nataan reklame di $\mathrm{K}$ ota Medan ( Aldy \& R izal, 2013: 19) , menunjukkan kawasan inti kota Kota Medan menempatkan reklame di 1 uar s arana $d$ an prasarana kota yaitu pa da bangunan p ribadi yang $\mathrm{m}$ embuka $\mathrm{t}$ oko $\mathrm{m}$ aupun jasa, serta kios-kios di sepanjang jalan tersebut. 

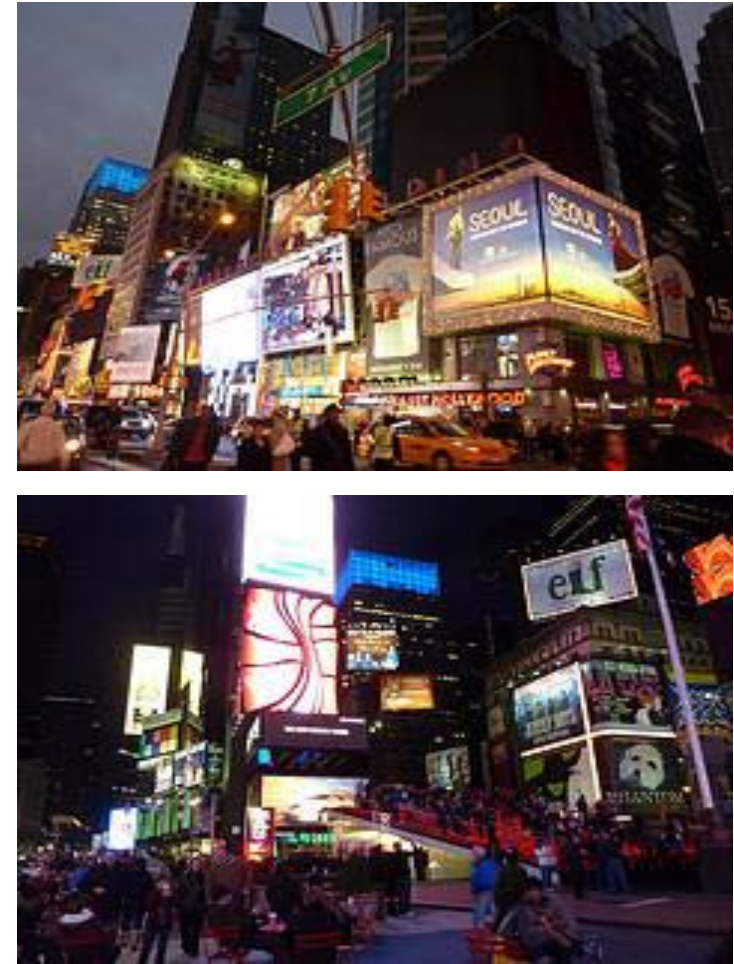

Sumber:

http://flickrhivemind.net/Tags/advertising,lcd/Interesting

Selain itu teknologi terbaru yang dapat diterapkan a dalah teknologi Media Façade. Teknologi s erupa $t$ elah di aplikasikan di fasad bangunan Mal T aman Anggrek, Jakarta. D i 1 uar ne geri teknologi i ni s udah diterapkan pada $t$ ampak eks terior ba ngunan Mal Ion Orchard, Singapura dan area Times Square, $\mathrm{N}$ ew Y ork, A merika $\mathrm{S}$ erikat s erta Hachiko S quare di T okyo, J epang. Media Façade adalah layar Light E mitting D iode (LED) yang di pasang $\mathrm{p}$ ada rangka tertentu, terintegrasi s erta $\mathrm{m}$ emanfaatkan $\mathrm{t}$ ampak eksterior ba ngunan. $\mathrm{H}$ al i ni da pat memperkuat ci tra $\mathrm{b}$ angunan, estetika lingkungan serta ci tra ka wasan tempat bangunan tersebut berada dan juga citra kota

secara k eseluruhan. Teknologi Media Façade diusulkan unt uk $\mathrm{z}$ ona ka wasan khusus yang menjadi representasi citra kota Semarang, seperti ka wasan oleh-oleh di jalan Pandanaran dan dapat memuat $\mathrm{n}$ ama toko/badan us aha serta i klan kom ersial a tau sosial.

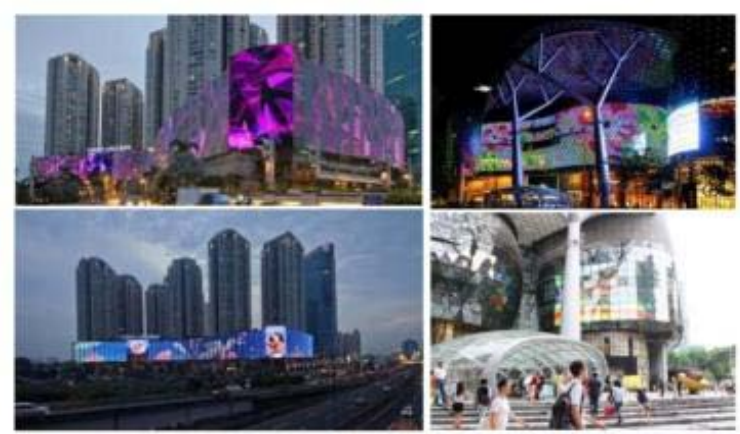

Sumber: http://vjfader.com, http://lighttalk-viaverlag.com, http://sumabeachlifestyle.com.

Gambar Aplikasi M edia F açade di Mal T aman Anggrek, Jakarta ( kiri a tasbawah) dan di Mal Ion Orchard, S ingapura (kanan atas-bawah).

\section{SIMPULAN}

Papan reklame yang $r$ api t ertata, bisa menjadikan c itra kot a menjadi 1 ebih ba ik, indah da $\mathrm{n} \mathrm{m}$ empunyai e stetika $\mathrm{t}$ ersendiri bagi pe nghuninya. $\mathrm{N}$ amun pe rlu diperhatikan ba hwa tidak s emua $\mathrm{j}$ alan atau koridor selalu ada reklame yang terpampang begitu mencolok dan menganggu keindahan kota. 
Demikian pula bagi koridor jalan yang mempunyai simpul a tau ruang publik, perlu dipikirkan apakah perlu ada papan reklame. Banyak catatan yang perlu dipikirkan antara lain:

a. Keamanan bagi pe makai j alan, karena diperlukan ke seimbangan pe ngendalian kesemrawutan dan penciptaan perhatian.

b. Kondisi dan suasana kota yang rural dan akan be rubah $m$ enjadi ur ban, $m$ aka diperhatikan kondi si 1 alu 1 intas yang crowded, j alan yang masih 2 arah, citra kota dan masalah keamanan.

5 koridor jalan yang dipilih merupakan pilar atau i kon kot a $\mathrm{S}$ emarang, $\mathrm{n}$ amun de mikian nampaknya pe rlu memeriksa s ecara keseluruhan ko ridor $\mathrm{j}$ alan 1 ain yang be lum termaktub da lam pe nelitian i ni. $\mathrm{H}$ arapnnya ke depan selain media fasade yang menjadi fokus $\mathrm{s}$ aat $\mathrm{i}$ ni bi sa di kembangkan 1 ebih melalui media lainnya seperti videotron, still baliho, ambience $\mathrm{m}$ edia, MMT $\mathrm{m}$ edia, wayfinding, $s$ treet $\mathrm{f}$ urniture, node ( ruang terbuka), m egatron, LED da $\mathrm{n} w$ ahan 1 ain untuk reklame.

\section{DAFTAR PUSTAKA}

Buku

(1) Hartanto, R obin dkk. 2013. E ditor. PUBLIK DAN REKLAME DI RUANG KOTA J AKARTA. Penerbit $\mathrm{R}$ uang Rupa B ekerja S ama de ngan Tifafoundation, $\mathrm{J}$ urnal $\mathrm{K}$ arbon $\mathrm{d}$ an Pusat $\mathrm{S}$ tudi $\mathrm{H}$ ukum da $\mathrm{nK}$ ebijakan Indonesia.

(2) The, $L$ iang $G$ ie. 1976. Garis B esar Estetik (Filsafat K eindahan), Fakultas Filsafat, Universitas $\mathrm{G}$ adjah MadaYogyakarta

(3) Lydia, 2011. Pemanfaatan warna unt k fasade di namis, $\mathrm{P}$ rosiding $\mathrm{S}$ eminar Nasional A VoER ke -3 Palembang, 26 27 Oktober 2011.

Jurnal

(1) Jurnal A rsitektur U niversitas Bandar Lampung, J uni 2013 . Identifikasi Penataan Reklame di $\mathrm{K}$ ota $\mathrm{M}$ edan. Pedia Aldy dan Muhammad Rijal.

(2) Jurnal I lmiah Perancangan Kota da $n$ Perancangan Kota, Enclosure V ol. 61 Maret 2007. Penataan Papan Reklame pada $\mathrm{P}$ enggal J alan H ayam W uruk. B . Aji Murtomo.

(3) Seri K ajian Ilmiah, Vol. $15 \mathrm{~N}$ omor 1 Januari 2013. S ignifikansi $P$ apan Reklame di $\mathrm{P}$ usat $\mathrm{K}$ ota $\mathrm{S}$ emarang. Yulita $T$ itik Sunarimahingsih dan Robert Rianto Widjaya. 
(4) Lily M auliani, 2010, F ungsi da n pe ran jalur pe destrian bagi pe jalan kaki, Sebuah Studi Banding Terhadap Fungsi Pedestrian, NALARs Volume 9 No 2 Juli $2010: 165-176$

Digital Media

(1) Artur Lugmayr, 2013, Ambient m edia today and tomorrow What have ambient media i n common? W hat ar e am bient mediatoday? Where will ambient media be in 2020?,Multimed Tools Appl. DOI 10.1007/s11042-012-1346-z, S pringer, Published O nline 23 F ebruary 2013. Diakses $20 \mathrm{~J} \quad$ anuari 2014. http://www.toxel.com/inspiration/2009/ 02/26/clever-and-creative-crosswalkadvertising/http://campaignsworthsharin g.com/2012/07/02/saving-water-indenver-colorado/

(2) Discussion Paper Digital Billboards and Road Safety: An Analysis of Current Policy and Research Findings, 2010, D iakses pa da Kamis, 15 Januari 2015, darihttp://oma.org.au/_data/assets/pdf_ file/0013/3127/Discussion_paper_Digita 1_signage_and_road_safety_SEPT_2010 .pdf

(3) Bartolomeus, Leonhard, 2013, Jakarta Modern: Selamat Tinggal Billboard, Selamat Datang LED, dalam Publik dan
Reklame di R uang Kota J akarta, Ruangrupa, Jakarta

(4) DKI Minta Perusahaan Pemilik Serat Optik Bangun Saluran Bersama, 2013, Diakses pa da Kamis, 15J anuari 2015, darihttps://tekno.liputan6.com/read/669

262/dki-minta-perusahaan-pemilikserat-optik-bangun-saluran-bersama

(5) Pajak Reklame: Pemkot Semarang Targetkan Pendapatan Rp1,3 Miliar, 2013, D iakses pa da Kamis, 15 Januari 2015 , darihttp://kabar24.bisnis.com/read/2013 0609/78/143682/pajak-reklame-pemkotsemarang-targetkan-pendapatan-rp13miliar

(6) Riset: Media Internet Penyumbang Terbesar Pertumbuhan Belanja Iklan, 2013, D iakses pa da Kamis, 15 Januari 2015 , darihttp://bisnis.news.viva.co.id/news/re ad/431266-riset--media-internetpenyumbang-terbesar-pertumbuhanbelanja-iklan 